\title{
Toy Recalls and China: Emotion vs. Evidence
}

\author{
Paul W. Beamish' and Hari Bapuji ${ }^{2}$ \\ 'University of Western Ontario, Canada, and ${ }^{2}$ University of Manitoba, Canada
}

\begin{abstract}
Product recalls in 2007 raised serious questions about the safety of products made in China and resulted in widespread outrage. Our analysis of toy recalls in the USA between 1988 and 2007 revealed that the vast majority of recalls were due to flaws in product designs, conducted in the corporate headquarters of toy companies, rather than to poor manufacturing by factories in Asian countries. We also found that the recalls have increased over the years, due both to design and manufacturing flaws. Our findings generated widespread interest and influenced the course of debate on import product safety. Our findings and experiences have significant implications for the research on product quality in international operations and the role that systematic research evidence can play in shaping management practice and public debate.
\end{abstract}

KEYworDs China, evidence based management, global supply chains, product recalls, toy recalls

\section{INTRODUCTION}

According to many observers, 2007 will go down in history as the 'year of recalls'. Millions of products, many made in China, were recalled in 2007. According to US regulators, tainted pet food imported from China was responsible for the deaths of, or injuries to, about 4,000 cats and dogs. As a result, regulators initiated the biggest pet food recall in US history. This was followed by worldwide recalls of Chinese toothpaste laced with an anti-freeze called diethylene glycol, which was found to be responsible for nearly 200 deaths in Haiti and Panama. Shortly thereafter, Chinese-made tires were linked to two deaths in a car accident in the USA and recalled. The tires lacked a safety feature that prevented tire treads from splitting and falling apart (Bapuji \& Beamish, 2008a).

The outrage that followed product recalls was revealed in several consumer surveys conducted during the second half of 2007. For example, in a poll conducted by Reuters/Zogby, the majority of people (close to 80 percent) reported that they were apprehensive about buying goods made in China. Nearly two-thirds (63 percent) of the respondents reported that they were likely to participate in a 
boycott of Chinese goods until the Chinese government improved the regulations governing the safety of the goods exported to the USA (Ryan, 2007).

This sort of sentiment against Chinese-made products potentially has serious implications for global trade. At a summit of North American political leaders in Canada, the heads of government of Canada, the USA and Mexico decided to crack down on unsafe goods, particularly those designed for children. The US Senate as well as the US House of Representatives held extensive hearings on the safety of imported products. The EU Consumer Commissioner, Meglena Kuneva, initiated an extensive review of the strengths and weaknesses of the consumer product safety mechanisms in Europe. The government of Brazil decided to halt the import of toys by Mattel until the safety issues were resolved.

In what appeared to be a counteroffensive, China rejected North American imports such as frozen pig kidneys imported from the USA and frozen pork spareribs from Canada. These products were found to contain residues of ractopamine, forbidden for use as a veterinary medicine in China. Also, China rejected shipments of US-made orange pulp and dried apricots containing high levels of bacteria and preservatives (Bapuji \& Beamish, 2008b).

As emotions and rhetoric ran high, besides claims and counterclaims, very little systematic evidence was forthcoming. In this context, we analysed the data on toy recalls and published two papers (Bapuji \& Beamish, 2007; Bapuji, Beamish, \& Laplume, 2007). These papers were reported in hundreds of media outlets around the world and underscored the power of systematic evidence to shape management practice and public debate. At the same time, they also highlighted the importance of evidence based management and the role that academics can play by bringing to bear timely and systematic evidence on vital issues. This paper is aimed at discussing these aspects and encouraging research on product safety in the context of international business.

The remainder of this paper is organized as follows. We begin by discussing the recent emergence of evidence based management in management research and research evidence on product recalls. Then, we summarize the major findings from our studies and their relevance in the context of the debate on import product safety. Finally, we discuss the implications of our findings for the research on product quality in international operations and elaborate the implications of our experience for the research aimed at impacting management practice by bringing research evidence to the fore.

\section{PRODUCT REGALLS AND EVIDENGE BASED MANAGEMENT}

According to the US Consumer Product Safety Commission (CPSC, 2008), recalls have increased drastically in the 2000s and a vast majority of the recalled products were made in China. Not surprisingly, consumers were outraged at China. However, as Lyles, Flynn, and Frohlich (2008) discussed, the issue of product quality 
in global supply chains is a complex managerial issue. The quality of import products has fallen as a result of many factors, including the trade policies of the USA, poor regulatory regimes in China, the squeezing of suppliers by big-box retailers, poor supply chain management and a focus on branding at the expense of quality by companies (Teagarden, 2007; Thompson, 2007; Wallach, 2007). Luo (2008) attributed part of the cause to moral degradation and poor organizational control.

As pointed out by these experts, a number of factors may have contributed to increased product recalls. However, rectifying the problems would require a systematic examination of the evidence about the antecedents of increased recalls and what managers can do about them. In the absence of evidence, any changes to management practices might not only fail to deliver the intended results, but also waste large financial and managerial resources.

Evidence based management $(\mathrm{EBM})$ is an established model for practice in fields such as medicine, nursing and public policy. Recently, several management scholars (Pfeffer \& Sutton, 2006; Rousseau, 2006a) have begun to tout the advantages of evidence based management. Evidence based management 'derives principles from research evidence and translates them into practices that solve organizational problems' (Rousseau, 2006a, p. 256). Consequently, the practice of EBM would mean decisions that are based on scientific evidence and thus free from biases, personal preferences and unsystematic experiences (Rousseau, 2006a).

Several scholars have argued that evidence based management would win in the market place for ideas (Cascio, 2007) and reduce the gap between management research and practice (Rousseau, 2007). Accordingly, some leading researchers argued for collaboration between academics and practitioners and for reviewing the research publication process. Summarizing these recommendations, Rynes (2007) exhorted researchers to tip the trend to more relevant research.

The calls for evidence based management were not without resistance. It has been argued that all evidence is subject to interpretation and will engender political behaviour (Learmonth, 2006). Also, unlike the sciences, 'there are no verifiable truths in management' (Tung, 2006, p. 508). In a spirited critique of EBM, Arndt and Bigelow (2007) argued that EBM assumes that decision-making is a linear process and ignores organizational and contextual differences. They point to the lack of empirical evidence to prove the effectiveness of EBM and conclude that EBM privileges a particular form of evidence - research, particularly quantitative research.

Notwithstanding the debate on the quality of evidence and the effectiveness of EBM, there is agreement among scholars that systematic research evidence is useful for practice (Learmonth, 2006; Rousseau, 2006b). Therefore, it is important to examine the available rescarch evidence on product recalls to understand how and why product recalls occurred and how they could be decreased.

The research on product recalls is very sparse. For example, a search for 'product recall' in the scholarly journals of Proquest databases yielded a total of 184 
papers for all dates. Clearly, this is a very small number. The majority of these papers were published in quality management journals. The few papers in the management and associated journals revealed no studies aimed at examining the safety of imported products. There were no studies that examined whether offshoring or outsourcing increased product recalls. Further, no studies examined how recalls can be decreased.

The extant research on product recalls was focused on the consequences of recalls, such as the erosion of stock price (Davidson \& Worrell, 1992; Govindaraj \& Jaggi, 2004; Rhee \& Haunschild, 2006) and consumer responses (Dawar \& Pillutla, 2000; Klein \& Dawar, 2004). Research attention was also directed toward understanding certain famous recalls such as the Pinto recall (Dardis \& Zent, 1982), how to conduct recalls in general (Smith, Thomas, \& Quelch, 1996) and communicate them to the public (Gibson, 1995). Very rarely did researchers examine the plausibility of learning from recalls (For an exception, see Haunschild \& Rhee, 2004).

In sum, the debate on product recalls has been filled with claims and counterclaims. However, the extant research on product recalls has provided very little evidence about the effect of outsourcing and offshoring on product safety and how product recalls may be reduced. Therefore, this issue is in need of urgent examination in view of the widespread belief that Chinese manufacturing is of poor quality.

\section{TOY RECALLS AND GHINA - PRELIMINARY EVIDENCE}

Our study is set in the US toy industry, which had estimated annual sales of US\$22.3bn in 2006. Over the years, US toy companies shifted their production overseas and focused their domestic operations on product design, marketing, research and development and other high value activities. As a result, more than 90 percent of the US demand for toys is met through imports (Bapuji et al., 2007). Considering the extent of offshoring in the US toy industry, it is an ideal setting to examine if offshoring has indeed decreased product quality and compromised consumer safety.

The safety of toys and other children's products in the USA falls within the jurisdiction of the Consumer Product Safety Commission (CPSC). Based on its analysis, the CPSC listed the following as the top hazards: magnets, recalled products, tip-overs (products such as televisions or bookcases that can tip over and crush young children), windows and coverings, and pool and spa drains (2008). Although some toys contain magnets, note that neither lead nor toys as such are listed among these top hazards, contrary to popular belief following 2007's toy recall publicity and outrage. According to the CPSC, 22 toy related deaths and an estimated 220,500 toy related injuries occurred in 2006 (Chowdhury, 2007).

The CPSC collects information about product safety issues from sources such as hospitals, doctors, newspaper reports, industry reports, consumer complaints, investigations conducted by its staff and reports from companies. When a company 


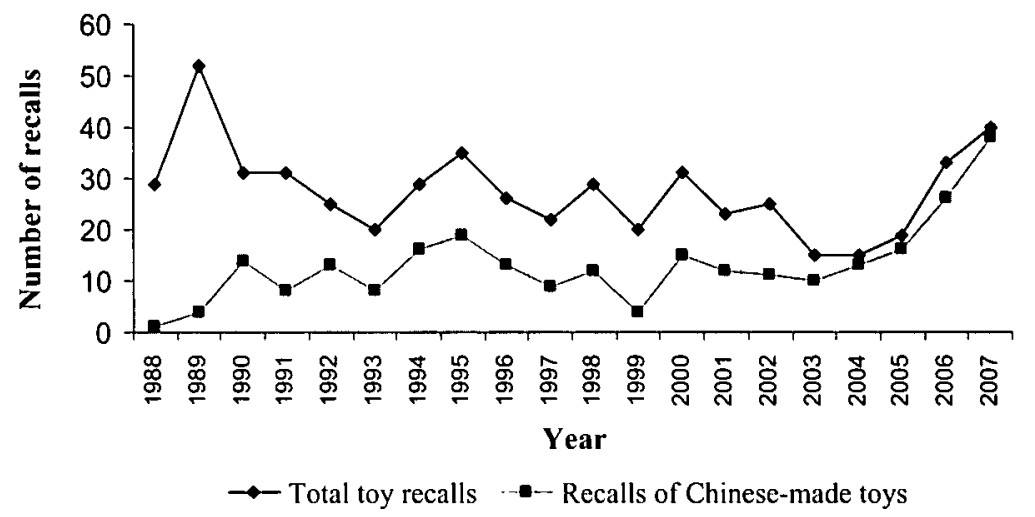

Figure 1. Toy rccalls over time

becomes aware of hazards associated with the products it sold, it is required by law to immediately, within 24 hours, inform the CPSC. Based on the information it received, the CPSC works in coordination with the companies involved to recall the hazardous products from the market. The recall notices are publicly available on the CPSC's website (http://www.cpsc.gov/).

The CPSC's recall notices contain information about the product being recalled, the company recalling the product, where the product was recalled, the hazard associated with the usage of the recalled product, sale details such as the number of units sold, sales locations, sale period and sale price, the procedure to return the product and the remedy offered by the company. Using the CPSC website, we compiled and analysed US toy recall data for the period 1988 to 2007. We used this data to explore the issue of import product safety and China in a systematic manner. Our two reports published by the Asia Pacific Foundation (Bapuji \& Beamish, 2007; Bapuji et al., 2007) were not funded or sponsored by any external organization or government. The current paper utilizes the data in these earlier reports.

\section{Total Toy Recalls vs. Recalls from China}

We counted the number of toy recalls issued each year from 1988 to 2007 (up to August) and the recalls of toys made in China. As presented in Figure 1, the number of recalls involving Chinesc-made toys appears to be on the rise over the last few years. The percentage of recalls that involved Chinese-made toys was hovering around 50 percent until 2002. However, since 2003, this figure was around 80 percent and reached 95 percent in 2007.

The implication of the dramatic rise in recalls of Chinese-made toys is somewhat misleading, though, because many assume that, for every recall of a Chinese-made toy, the responsibility lies completely with the Chinese suppliers. This is simply 
wrong. It masks the fact that Chinese suppliers are only involved in manufacturing the toys and not in designing them. Second, the rise in recalls does not take into account the rise in imports of Chinese-made toys. We examine these two aspects in turn.

\section{Toy Recalls - Design vs. Manufacturing Flaws}

In order to better understand which parts of the supply chain contributed to the recall, we distinguished between design and manufacturing related defects. Design defects include such things as the use of small detachable parts, like button eyes and beads as well as the use of strings and awkward spaces that can lead to strangulation or entrapment. Manufacturing defects include the use of toxic chemicals (such as the high lead content found in some toys), faulty assembly, or substandard parts. The responsibility for design problems usually lies with toy companies in the West that provide the designs. By contrast, the responsibility for manufacturing problems lies mostly with overseas toy manufacturers (Bapuji \& Beamish, 2007; Bapuji et al., 2007).

We coded the recalls as either 'manufacturing related' or 'design related' based on the information provided in the recall notices. In about 10 percent of the cases, it was not possible to conclude from the information provided if the problem was a design or a manufacturing flaw. ${ }^{[1]}$ In such cases, we coded the flaw as 'not sure' and omitted it from our analysis. The coding was replicated independently by four people, two of whom were not directly associated with this research. The coding was highly reliable (Cohen's kappa $=0.86 \mathrm{p}<0.0001$ ). Although the assessment of defect type is 'subjective', the consistency of the coding gives us sufficient confidence in the results to allow us to draw conclusions about general patterns.

Of the 550 recalls since 1988, an overwhelmingly high number of recalls ( 420 or 76.4 percent of all recalls) were due to problems which could be attributed to design flaws. In contrast, only about 10 percent (or 54) of recalls are historically attributable to manufacturing defects such as poor craftsmanship, over-hcating of batteries, lead paint and inappropriate raw materials. In other words, the vast majority of recalls were made because of design related problems, not manufacturing defects.

As presented in Figure 2, we found that the number of recalls attributable to manufacturing remained roughly the same over the years but increased in the last two years. In fact, manufacturing flaws accounted for around 20 percent of the recalls in the last two years. Similarly, the number of recalls attributable to design flaws exhibits an upward trend.

\section{Toy Import and Recall Levels}

We collected US toy import statistics for NAICS 33993 (formerly SIC codes 3942, 3944) from 1992 to 2007 (the end of the third quarter), from the website of the 


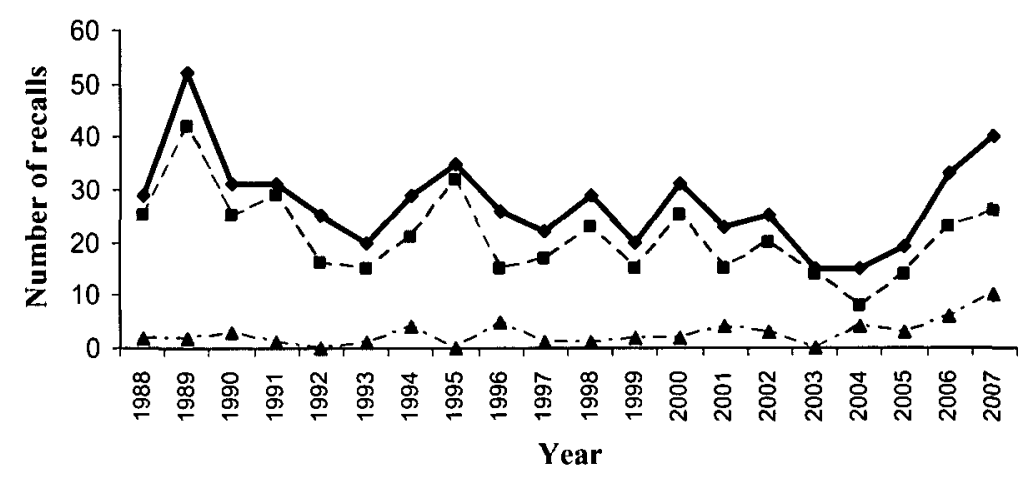

$\longrightarrow$ Total recalls $-\rightarrow-$ Design flaw recalls -- - Manufacturing flaw recalls

Figure 2. Recalls by flaw type

International Trade Administration (ITA) of the US Department of Commerce (http://trade.gov/index.asp). At the end of the third quarter of 2007, Chinese toy imports accounted for a full 88.2 percent of toy imports to the USA, up dramatically from 41 percent in 1992.

We used the import data to compute toy recalls as a percentage of toy imports. For this analysis, we relied on data from 1992 to 2007. ${ }^{[2]}$ About 30.1 percent of 349 recall notices did not include information on country of manufacture and were not included in this analysis; however, there appears to be no meaningful pattern behind these missing data. A further 2.9 percent of recall notices were excluded because they pertained to toys made in the USA, leaving us with a final sample of 233 data points.

Our interest was to examine if recalls of Chinese-made products were out of proportion with those of other countries. Since the imports data is counted in dollars, we computed a dollar measure for each recall by multiplying the number of units involved with its average sale price. We aggregated the dollar value of recalls by year and then divided it by the dollar value of imports for each year. Consequently, this measure approximates the percentage of imports that are recalled in each year. It does not capture the recalls as an exact percentage of imports because the sale price in the USA includes a margin over the import cost and thus will be higher than the cost of imports.

Continuing with the distinction made earlier, we computed the recalls as a percentage of imports for four different categories: (i) toys made in China and recalled for design flaws; (ii) toys made in China and recalled for manufacturing flaws; (iii) toys made outside China and recalled for design flaws; and (iv) toys made outside China and recalled for manufacturing flaws. We plotted the trend lines in Figure 3.

The trend lines, like regressions, are sensitive to outliers and should be interpreted with caution. Therefore, we combine our interpretation with the actual data 


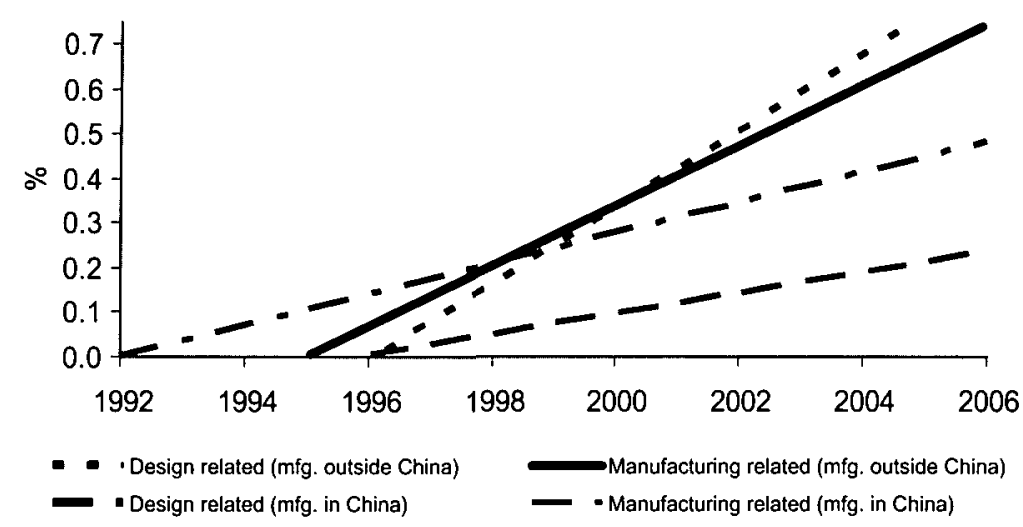

Figure 3. US toy recalls as percent of US toy imports (trend lines)

to conclude that recalls have increased over the years as a percentage of imports. However, the increase is most visible and consistent for design flaws. For example, in 2006, about one percent of all the toys imported from China were recalled for design flaws, whereas one twentieth of one percent (or 20-fold less) were recalled for manufacturing flaws. Also, the increase in recalls, both for manufacturing and design flaws seems to be less pronounced for Chinese-made toys than it is for the toys made outside China.

Overall, the evidence points to an increase in toy recalls. However, that increase is not necessarily attributable to Chinese manufacturing. The majority of recalls, over the years, have been for design flaws. Despite the avowed specialization of Western toy companies on design and development, there is little evidence to suggest that design flaws have decreased over the years. Similarly, although at a lesser pace compared with design flaws, the recalls due to manufacturing flaws have increased. Finally, although recalls of Chinese-made toys have been increasing, it is at a slower pace compared with other countries. Clearly, there seems to be a need to take a more objective approach to the problem than making charges and counter charges.

\section{Media Attention to the Research Evidence}

As previously mentioned, these data first appeared in the two reports (Bapuji \& Beamish, 2007; Bapuji et al., 2007) with the Asia Pacific Foundation of Canada, a government funded, independent think-tank focused on the relations between Canada and the Asia-Pacific region. The reports were made available freely to the media and general public. Beginning with reports on the CBC TV (http:// www.cbc.ca/MRL/clips/rm-hi/freedman-toys070907.rm) and CBC online edition (http://www.cbc.ca/news/story/2007/09/07/toy-study.html) on September 7, 2007, our findings were subsequently reported by a number of major 
media outlets around the world, including the Financial Times, Business Week, the Wall Street Journal, the New York Times, GNN, the Washington Post, USA Today, the Sydney Morning Herald, the People's Daily and the Straits Times. We were interviewed multiple times on TV and Radio channels such as CBC TV, CTV, CBC Radio, $\mathrm{BBC}$ and Voice of America. The reports were requested by the representatives of the US and Canadian governments, as well as several stakeholders of the toy industry.

Before the publication of these findings, the media reports focused only on toy recalls due to excess lead paint. Following the publication of our findings, they began to mention both lead paint and design flaws in the same breath. On September 21, 2007, Mattel apologized to the Chinese government for the damage caused to the reputation of Chinese manufacturers because they were wrongly associated with the magnets recall, which was a result of design flaws. Several news media mentioned our studies in their reports of Mattel's apology.

\section{DISCUSSION}

Our research on toy recalls has two implications. First, the patterns in the data that we found imply some important research questions for international business. Second, our research has implications for the growing calls for evidence based management and the potential impact on practice. We discuss each of these implications in turn.

\section{Product Recalls and International Business}

Our data revealed that toy recalls due to design flaws have not only been higher, but increased at a much faster rate over the years compared with recalls due to manufacturing flaws. In other words, contrary to popular belief and the assertions of some executives, toy recalls have not increased as a result of manufacturing shifting to China. In reality, the toy recalls have increased across the board for design as well as manufacturing flaws. However, the public outrage was decidedly against Chinese manufacturing. Considering the implications of such outrage for international business, it is important to examine the issue of product quality in international operations. Two broad research questions are worth examining. Why has there been an increase in recalls for both design and manufacturing flaws in global supply chains? Why have the stakeholders assigned blame to China that is disproportionately higher than the actual responsibility of Chinese suppliers for product recalls?

Since the 1980s, companies in different countries have specialized in different points on the value chain of toy making; the large toy companies in the West have specialized in design, development and promotion of toys, whereas the companies in Asia, particularly China, have specialized in manufacturing toys. Research 
evidence so far suggested that, as companies specialize and gain more experience, their performance and productivity increases (Darr, Argote, \& Epple, 1995). However, instead of decreasing, the recalls have increased over the years. What are the reasons for this increase? Have specialization and geographical separation resulted in a lack of coordination between design and manufacturing activities (Adler, 1995)?

The increase in design flaws might reflect a failure to learn by using internal and external knowledge about the safety implications of designs (Bapuji \& Beamish, 2008c). However, the increase in manufacturing flaws might be due to loose coupling in the global toy supply chains (Lyles et al., 2008). These are issucs that are worthy of examination. Answers to these questions can ensure that the benefits of international operations can be maximized by lessening the slippages in supply chains.

It would be useful to examine the firm level variation in recalls and the causes for it. Prior research indicated that firms learn more from recalls that are voluntary (Haunschild \& Rhee, 2004). The extent of voluntariness in consumer product recalls cannot be ascertained because all recalls are conducted together by the CPSC and the companies involved. However, it would be useful to examine if firms learn from any other recall characteristics such as experience with prior recalls, speed of recall, or the scope of recall.

Our research revealed that the outrage against China for toy recalls was somewhat misplaced. When our findings were reported, several industry experts agreed with the findings and pointed out that lead paint has never been a big concern. The single largest cause of recalls, deaths and injuries involving toys was small parts, which is, of course, a design flaw as opposed to a manufacturing error. Despite this knowledge, the media, some toy company executives and the public blamed China for virtually all the flaws in toy recalls.

Attributions of blame in a crisis situation are tricky and complex. To a large extent, the blame depends on who is assigning it. It is possible that managers of toy companies might try to attribute the blame for failures such as product recalls on the environment, including suppliers. When the suppliers are located in an offshore location, it is even easier for the managers to blame them. For example, when Mattel announced its recall of toys due to design as well as manufacturing flaws, its CEO clearly attributed the recalls to Chinese suppliers (Bapuji \& Beamish, 2007, 2008b).

The reasons why media and consumers attributed the problem of product recalls to China might be more complex than why toy company managers blamed Chinese suppliers. These reasons might originate in the cognitive biases of consumers who perceive the products made in a foreign country to be of lower standard than those made in their own environment. The often reported inadequacies of the regulatory system in China and the incidences of corruption further fueled the perception of weak legal or ethical standards. In short, as Barney and 
Zhang (2008) discuss, the outrage may have been influenced by the national image of China. The issue with toys takes on an added dimension of concern due to the emotional attachment that consumers have to children and their safety. It would be useful to examine these aspects in detail to separate emotions from reality and to understand the role of cognitive biases for attributions of responsibility and emotional reactions. Insights generated from such research are likely to be useful in managing similar situations in the future and improve trade relations between nations.

\section{Evidence Based Management and Implications for Practice}

Recently, there have been growing calls for evidence based management and research that could make an impact on practice by providing evidence. Our experience provides a case in point. The impact that our research had on public opinion was immediate and visible. It is premature to assess, at least for now, if our findings had any impact on management practice. However, it is safe to assume that given the attention to design flaws, toy companies will make greater efforts to reduce them. At the least, our research reinforces the need to address both design flaws and manufacturing flaws. Hopefully, the two earlier reports (Bapuji \& Beamish, 2007; Bapuji et al., 2007) along with the current essay point to the importance of providing relevant data to managers so that they can reflect on the problems they face.

In this research, we explored the phenomenon by using evidence and data in a systematic way. As recently pointed out by Hambrick (2007), a deep and systematic description of the phenomenon is a necessary step preceding the generation of theory to explain it. More importantly, the systematic evidence is more likely to influence management practice than opinions or unsubstantiated theories. The vast majority of the media people who contacted us (from all countries) appreciated the data we offered in analysing the toy recall situation.

Toy recall is not the only area where scholars can bring evidence to bear on societal issues. Real opportunities exist for researchers willing to explore issues of relevance in a systematic manner and provide the evidence needed for managers to reflect and act accordingly.

\section{NOTES}

[1] The recall notices are often carefully crafted not to place blame so as to avoid future litigation for the companies involved (Felcher, 2001). The issue of how companies and the CPSC negotiate every word in the recall notice and history behind it is interesting, but beyond the scope of this paper. Suffice it to say that cvery word in a recall notice must be agreed upon by the company involved in the recall.

[2] We had to omit the recalls data from 1988 to 1991 because the data on country of manufacturing were missing for a large number of the recalls during this period. 


\section{REFERENCES}

Adler, P. S. 1995. Interdepartmental interdependence and coordination: - The case of the design/ manufacturing interface. Organization Science, 6: 147-167.

Arndt, M., \& Bigelow, B. 2007. Evidence-based management in health care organizations: A critique of its assumptions. Academy of Management Best Paper Proceedings. Philadelphia. Briar Cliff Manor, New York: Academy of Management.

Bapuji, H., \& Beamish, P. 2007. Toy recalls: Is China really the problem? Vancouver: Asia Pacific Foundation of Canada. [Cited 5 Fcb. 2008.] Available from URL: http:// www.asiapacific.ca/analysis/pubs/pdfs/commentary/cac45.pdf

Bapuji, H., \& Beamish, P. 2008a. Mattel and the toy recalls (A). London, Canada: Ivcy Publishing, 9B08M010.

Bapuji, H., \& Beamish, P. 2008b. Mattel and the toy recalls (B). London, Canada: Ivcy Publishing, 9B08M011.

Bapuji, H., \& Beamish, P. 2008c. Product recalls: Avoid hazardous design flaws. Harvard Business Review, 86(3): 23, 26.

Bapuji, H., Beamish, P., \& Laplume, A. 2007. Toy import and recall levels: Is there a connection? Vancouver: Asia Pacific Foundation of Canada. [Cited 5 Feb. 2008.] Available from URL: http://www.asiapacific.ca/analysis/pubs/pdfs/rr/2007/toyrecalls.pdf

Barney, J., \& Zhang, S. 2008. Collective goods, free riding, and counting brands: The Chinese experiencc. Management and Organization Reviez, 4: 211-223.

Cascio, W. 2007. Evidence-based management and the market place for idcas. Academy of Management Joumal, 50: 1009-1012.

Chowdhury, R. 2007. Toy related deaths and injuries calendar year 2006. Washington, DC: Consumer Product Safety Commission. [Cited 17 Mar. 2008.] Available from URL: http:// www.cpsc.gov/library/toymemo06.pdf

CPSC (Consumer Product Safety Commission). 2008. CPSC releases the 'Top Five Hidden Home Hazards'. Consumer Product Safety Review, 12(1): 1-3.

Dardis, R., \& Zent, C. 1982. The cconomics of the Pinto recall. The Journal of Consumer Affairs, 16: 261-277.

Darr, E. D., Argote, L., \& Epple, D. 1995. The acquisition, transfer, and depreciation of knowledge in service organizations: Productivity in franchises. Management Science, 41: 1750-1762.

Davidson, W. N., \& Worrell, D. L. 1992. The effect of product recall announcements on shareholder wealth. Strategic Management Journal, 13: 467-473.

Dawar, N., \& Pillutla, M. 2000. The impact of product-harm crises on brand equity: The moderating role of consumer expectations. Journal of Marketing Research, May: 216-226.

Felcher, M. 2001. It's no accident: How corporations sell dangerous baby products. Monroe, ME: Common Courage Press.

Gibson, D. 1995. Public relations considerations of consumer product recall. Public Relations Revieze, 21: 225-240.

Govindaraj, S., \& Jaggi, B. 2004. Market over rcaction to product recall revisited - The case of Fircstone tires and the Ford explorer. Revieze of Quantitative Finance and Accounting, 23(1): $31-54$.

Hambrick, D. 2007. The field of management's devotion to theory: Too much of a good thing? Academy of Management Joumal, 50: 1346-1352.

Haunschild, P., \& Rhec, M. 2004. The role of volition in organizational lcarning: The case of automotive product recalls. Management Science, 50: 1545-1560.

Klein, J., \& Dawar, N. 2004. Corporate social responsibility and consumers' attributions and brand evaluations in a product-harm crisis. International Journal of Research in Marketing, 21: 203-217.

Learmonth, M. 2006. 'Is there such a thing as "Evidence-Based Management"?': A commentary on Rousseau's 2005 presidential addrcss. Academy of Management Revieze, 31: 1089-1093.

Luo, Y. 2008. A strategic analysis of product recalls: The rolc of moral degradation and organizational control. Management and Organization Revieze, 4: 183-196.

Lyles, M. A., Flynn, B. B., \& Frohlich, M. T. 2008. All supply chains don't flow through: Understanding supply chain issues in product recalls. Management and Organization Revieze, 4: 167-182. 
Pfeffer, J., \& Sutton, R. I. 2006. Hard facts, dangerous half-truths \& total nonsense: Profiting from evidence-based management. Boston, MA: Harvard Busincss School Press.

Rhec, M., \& Haunschild, P. 2006. The liability of good reputation: A study of product recalls in the U.S. automobilc industry. Organization Science, 17: 101-117.

Rousscau, D. M. 2006a. Is there such a thing as 'cvidencc-based management'? Academy of Management Reviere, 31: 256-269.

Rousseau, D. M. 2006b. Kecping an open mind about cvidence-based management: A Reply to Lcarmonth's commentary. Academy of Management Reviewe, 31: 1089-1093.

Rousscau, D. M. 2007. A sticky, leveraging, and scalable strategy for high-quality connections betwcen organizational practice and sciencc. Academy of Management Journal, 50: 10371042.

Ryan, M. 2007. One in four Amcricans 'very worricd' by China imports. Reuters, 19 Sep. Available from URL: http://www.signonsandiego.com/news/nation/20070919-0400-usa-foodsafetypoll.html.

Ryncs, S. 2007. Let's create a tipping point: What academics and practitioncrs can do, alonc and together. Academy of Management Journal, 50: 1046-1054.

Smith, C. N., Thomas, R.J., \& Quclch, J. A. 1996. A strategic approach to managing product recall. Harvard Business Revieve, 74: 102-112.

Teagarden, M. 2007. Protecting Children from Lead Tainted Imports. Testimony to the U.S. Congress. [Cited 20 Sep. 2007.] Available from URL: http://encrgycommercc.housc.gov/ cmtc_mtgs/110-ctcp-hrg.092007.Teagarden-testimony.pdf

Thompson, A. 2007. Protecting Children from Lead Tainted Imports. Testimony to the U.S. Congress. [Cited 20 Sep. 2007.] Available from URL: http://cnergycommerce.house.gov/ cmtc_mtgs/110-ctcp-hrg.092007. Thompson-testimony.pdf

Tung, R. 2006. Of arts, leadership, management education, and management rescarch: A commentary on Nancy Adlcr's 'The Arts \& Leadership: Now That We Can Do Anything, What Will We Do?' Academy of Management Learning and Education, 5: 505-511.

Wallach, L. 2007. Protecting Children from Lead Tainted Imports. Testimony to the U.S. Congrcss. [Cited 20 Sep. 2007.] Available from URL: http://cncrgycommerce.housc.gov/ cmtc_mtgs/ 1 10-ctcp-hrg.092007. Wallach-testimony.pdf

Paul W. Beamish (pbeamish@ivey.ca) holds the Canada Research Chair in International Business at the Richard Ivey School of Business at the University of Western Ontario. Professor Beamish (Bao Ming Xin in Chinese) has worked on Asia specific issues for many years. He has conducted research and written case studies involving China, Hong Kong, Japan, Korea, Malaysia, Singapore, Taiwan and Vietnam.

Hari Bapuji (bapuji@cc.umanitoba.ca) is an assistant professor at the I.H. Asper School of Business, University of Manitoba, Canada. He received his Ph.D. from the Richard Ivey School of Business at the University of Western Ontario, Canada. His research examines organizational learning and knowledge and how they affect a variety of organizational phenomena.

Manuscript received: February 5, 2008

Final version accepted: March 17, 2008

Accepted by: Anne S. Tsui 